\title{
Long term effects of childbearing on health
}

\author{
VALERIE BERAL \\ From the London School of Hygiene and Tropical Medicine, Keppel Street (Gower Street), London WC1E \\ $7 H T$
}

SUMMARY Information on whether a woman had ever had any children was recorded for all deaths registered to ever-married women in England and Wales between 1938 and 1960. Analysis of the relation between parity and cause of death for 1.2 million women aged 45-74 years revealed that parous women had lower mortality from breast, ovarian, and endometrial cancer than did nulliparous women but a higher mortality from diabetes mellitus, gallbladder disease, cancer of the uterine cervix, nephritis and nephrosis, hypertension, ischaemic and degenerative heart disease, cerebrovascular disease, and all causes of death. There is a parallel between the long term effects of pregnancy and of oral contraceptives on health.

A woman's risk of developing various diseases is altered during the course of a pregnancy and in the immediate postpartum period. Pregnancy is also known to confer long term protection against certain cancers, for example, of the breast, ovary, and endometrium, but its effect on other conditions has rarely been studied. ${ }^{1}$ Reported here is an analysis of the relation between parity and cause of death for 1163341 married women aged 45-74 years who died in England and Wales between 1938 and 1960.

\section{Subjects and methods}

The Population Statistics Act (1938) of England and Wales required that for each ever-married woman aged 16 years and over an answer to the following question be recorded on the death certificate: "Had the deceased any children by her husband or any former husband? (yes/no)". ${ }^{2}$ Those for whom the response was "yes" or "no" are termed "parous" or "nulliparous", respectively, in this paper. Tabulations of this information, classified by 24 causes of death and into 10 year age groups, were published annually in the Registrar General's Statistical Reviews for England and Wales from 1938 until $1960 .^{3}$ Using these data, proportional mortality ratios (PMRs) were calculated for parous women relative to nulliparous women during the two time periods, 1938-49 and 1950-60, because there were changes in the International Classification of Diseases between 1949 and 1950 and also because the list of conditions tabulated changed at that time. PMRs rather than standardised mortality ratios (SMRs) were calculated for those time periods because appropriate denominators, classifying women of all ages according to their pregnancy history, were not available until the 1961 census. Since such data were available for $1961^{7}$ cause specific mortality rates and SMRs were calculated for the time period 1959-60 using the direct method of standardisation and the 1961 population of nulliparous women as the standard. Nulliparous women, rather than all women, were chosen as the standard population since they should represent a baseline "unexposed" group in analyses relating to parity and disease. All differences referred to are significant at the $5 \%$ level.

\section{Results}

Between 1 July 1938 and 31 December 1960 there were 1705394 deaths of ever-married women for whom parity was recorded. Data presented here are limited to the 1163341 deaths reported in women aged 45 to 74 years. This is because before the age of 45 years the presence of chronic illness may influence whether or not a woman has children and thus could produce spurious associations between parity and disease; and after 75 years of age information about parity and cause of death are less reliable than at younger ages.

Conditions with significantly high PMRs and SMRs in parous women are listed in table 1 . It can be seen that there is a strong consistency between the PMRs in each age group and at the different periods of time. The only exception is arteriosclerotic heart disease, for which the PMRs did not differ significantly from 100 in $1938-49$ but did in the 
Table 1 Conditions with a significantly higher mortality in parous than nulliparous married women. Age specific proportional mortality ratios (PMRS) for parous compared with nulliparous women for 1938-49 and 1950-60 and age-standardised mortality ratios (SMRs) for 1959-60

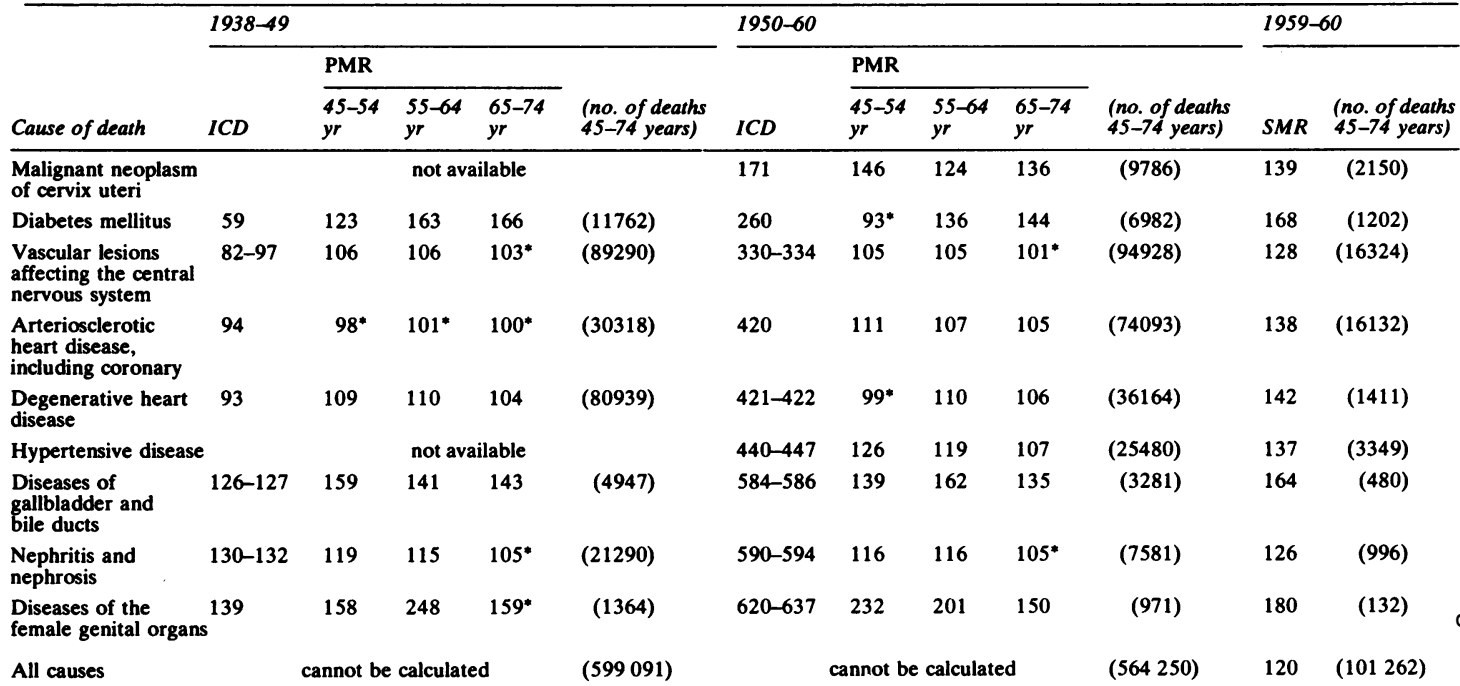

"Does not differ significant from 100 ( $p>0.05)$.

subsequent 11 years. Also, where the PMRs are elevated, so too are the SMRs, but the SMRs are less stable than the PMRs, being based on fewer deaths. The cause-specific SMRs tend to be higher than the corresponding PMRs, especially for conditions such as cerebrovascular and arteriosclerotic heart disease. This is because conditions that make a significant contribution to the total deaths in a population influence their own PMR, weighting it towards 100. The all-causes SMR for $1959-60$ was $20 \%$ higher in parous than in nulliparous married women (SMR 120 , see table 1 ).

Conditions that were associated with significantly low PMRs and SMRs in parous compared with nulliparous women are listed in table 2 . Here again the findings are consistent in the two time periods and at different ages. The conditions listed in table 30 showed no clear association with parity at ages $45-74$ years.

\section{Discussion}

These findings indicate that at ages well beyond the childbearing period nulliparous and parous ever-married women have differing mortality patterns. According to the data, nulliparous women are more likely than the parous to die from breast, ovarian, and endometrial cancer, whereas parous women are more likely to die from diabetes mellitus, gallbladder disease, and a number of circulatory

Table 2 Conditions with a significantly lower mortality in parous than nulliparous married women. Age specific proportional mortality ratios (PMRs) for parous compared with nulliparous women for the periods $1938-49$ and $1950-60$ and age-standardised mortality ratios (SMRs) for 1959-60

\begin{tabular}{|c|c|c|c|c|c|c|c|c|c|c|c|c|}
\hline \multirow[b]{3}{*}{ Cause of death } & \multicolumn{5}{|l|}{$1938-49$} & \multicolumn{5}{|l|}{$1950-60$} & \multicolumn{2}{|c|}{$1959-60$} \\
\hline & \multirow[b]{2}{*}{$I C D$} & \multicolumn{3}{|l|}{ PMR } & \multirow[b]{2}{*}{$\begin{array}{l}\text { (no. of deaths } \\
45-74 \text { years) }\end{array}$} & \multirow[b]{2}{*}{$I C D$} & \multicolumn{3}{|l|}{ PMR } & \multirow[b]{2}{*}{$\begin{array}{l}\text { (no. of deaths } \\
45-74 \text { years) }\end{array}$} & \multirow[b]{2}{*}{$S M R$} & \multirow[b]{2}{*}{$\begin{array}{l}\text { (no. of deaths } \\
45-74 \text { years) }\end{array}$} \\
\hline & & $\begin{array}{l}45-54 \\
y r\end{array}$ & $\begin{array}{l}55-64 \\
y r\end{array}$ & $\begin{array}{l}65-74 \\
y r\end{array}$ & & & $\begin{array}{l}45-54 \\
y r\end{array}$ & $\begin{array}{l}55-64 \\
y r\end{array}$ & $\begin{array}{l}65-74 \\
y r\end{array}$ & & & \\
\hline Cancer of breast & 50 & 83 & 74 & 76 & $(32623)$ & 170 & 88 & 80 & 76 & (35956) & 92 & (7131) \\
\hline $\begin{array}{l}\text { Cancer of ovaries } \\
\& \text { fallopian tubes }\end{array}$ & $\begin{array}{c}46 \\
\text { (part) }\end{array}$ & 57 & 58 & 59 & (9629) & 175 & 61 & 63 & 66 & $(13054)$ & 73 & (2461) \\
\hline $\begin{array}{l}\text { Cancer of corpus } \\
\text { uteri }\end{array}$ & \multicolumn{5}{|c|}{ not available } & & 62 & 61 & 63 & $(4162)$ & 74 & $(852)$ \\
\hline Syphilitic diseases & $\begin{array}{l}31,80 \\
83,96\end{array}$ & 51 & 64 & 75 & (2991) & $020-029$ & 59 & 63 & 65 & (1409) & 74 & (193) \\
\hline Uterine fibroma & \multicolumn{5}{|c|}{ not available } & 214 & 85 & 54 & 38 & $(462)$ & 54 & $(60)$ \\
\hline
\end{tabular}


Table 3 Conditions with no clear association with parity at ages 45-74 years

\begin{tabular}{l} 
Cause of death \\
\hline Anaemia \\
Cancers of other female genital organs \\
Diseases of veins \\
Chronic rheumatic heart disease \\
Tuberculosis \\
Thyrotoxicosis \\
Diseases of the adrenals \\
Hernia, intestinal obstruction \\
\hline
\end{tabular}

diseases including hypertension, ischaemic heart disease, and cerebrovascular disease. In 1959-60 parous married women aged 45-74 had an overall mortality rate $20 \%$ higher than that for nulliparous married women of comparable age. This was largely because of higher rates of circulatory diseases in parous compared with nulliparous women.

Some associations noted here are well known, namely, the decreased risks of breast, ovarian, and endometrial cancers in parous women. ${ }^{1}$ Uterine fibroids have long been associated with infertility. Whether this is the reason for their high frequency in older nulliparous women, or whether the nulliparity itself predisposes to the development of fibroids in later life, cannot be determined from these data. In contrast, the high rate of syphilis in nulliparous women is almost certainly because the condition or associated infections render women infertile, rather than the reverse. That parous women have increased rates of diabetes mellitus, gallbladder disease, cancer of the uterine cervix, ischaemic heart disease, and hypertension has been suggested before, but not all reports have been consistent. ${ }^{16-11}$ One reason for the contradictory findings is that there are a number of ways in which a positive relation between parity and disease may be defined: some investigators consider that a condition is related to parity if the disease rates differ in the parous and nulliparous, whereas others have looked for a trend in risk with increasing numbers of pregnancies or livebirths; and others have examined for relations between miscarriage and disease. Another source of confusion is that marital status has sometimes been used as a proxy for parity, and the consistently lower mortality of married compared with single women has been attributed to the generally beneficial effects of childbearing on health. The only other set of national statistics for England and Wales, from which mortality of nulliparous and parous ever-married women can be compared, is the Office of Population Censuses and Survey's (OPCS) Longitudinal Study, ${ }^{12}$ The findings broadly agree with those reported here, the only major difference being that parous women had a lower all-cause death rate than did nulliparous. The longitudinal study is recent, however. The numbers of deaths are small and refer to younger women, many of whom were of reproductive age at the time of death.

It is unfortunate that more detailed data on pregnancy history and other factors were not available for this study. Information on the number of livebirths, dates of pregnancies, and the numbers of miscarriages that each woman had would have permitted analyses of which aspects of pregnancy history correlated best with each disease. Nevertheless the information that was collected was reliable. ${ }^{2}$ Also no data on social class or obesity were available. Although in the past there was a marked gradient in the average family size according to social class, the proportion nulliparous differed very little-from $17 \%$ in the wives of professional workers to $18 \%$ in the wives of the unskilled. ${ }^{4}$ Thus the analyses presented here, separating parous and nulliparous, should not be strongly biased by social class. Obesity has been linked with high parity, ${ }^{13}$ but data from the past suggest that this may not always have been the case. ${ }^{14}$ Another disadvantage of these analyses is that appropriate information on the numbers of parous and nulliparous married women in England and Wales was not available for 1938-60. This necessitated the general use of proportional mortality analyses, rather than the calculation of age-specific and age-standardised mortality rates for that period. But the PMRs are unlikely to be biased. In an attempt to examine their validity, SMRs were calculated for the limited two-year period 1959-60, using population statistics from the 1961 census. Although the numerator and denominator do not cover exactily the same time period, and the numbers of deaths in the two years are small compared with those which formed the basis of the PMR analyses, it can be seen that the findings for the SMR and PMR analyses were very similar indeed (tables 1 and 2). Other comparisons of PMRs and SMRs using routinely collected data from OPCS also indicate that PMRs can be used as indicators of an increased frequency of disease in subgroups of the population. ${ }^{15}$

Perhaps the most fascinating aspect of these data is that the conditions related to childbearing are those that have also been linked to oral contraceptive use. Of the nine conditions listed in table 1 with high mortality in parous women, seven have been suggested as being increased in oral contraceptive users - three consistently so (coronary heart disease, cerebrovascular disease, and hypertension) and for the other four (gallbladder disease, cancer of the uterine cervix, diabetes mellitus, and other heart disease) the evidence is weak and sometimes contradictory. ${ }^{16-20}$ Of the five conditions listed in table 2 as being less frequent in parous women, two, ovarian and endometrial cancer, and possibly a third, 
uterine fibroids, are reported to be reduced in oral contraceptive users. ${ }^{162122}$

Although the data are not as comprehensive as one might have wished, they do raise a number of questions about the effects of pregnancy on health. Why is parity a predictor of the long term pattern of disease in women? Are there hormonal, physiological, or even social explanations for this, or are there selective forces in childbearing among women who are prone to certain disease? The Registrar General, examining the first year's return of these data in $1938,{ }^{2}$ ascribed the excess mortality from circulatory conditions in parous married women to the burden of caring for a large family. Considering, however, that oral contraceptives seem to have a similar relation to disease as does childbearing, an hormonal explanation for the associations seems more plausible than a social one. The data presented here are for generations of women who never took the pill. How might the effects of oral contraceptives combine with those of pregnancy? Some data suggest that for circulatory disease the risks may multiply - the highest disease rates being in multiparous women who had also taken oral contraceptives. ${ }^{17}$ Finally, if childbearing does have a direct long term effect on disease, how far could the changing patterns of disease in women over time be the result of the falling birth rate earlier in this century? Increasing rates of ovarian and breast cancer have already been linked to this. ${ }^{23}{ }^{24}$ Could the declining mortality from circulatory diseases-which has generally been more pronounced in women than in men $^{25}$ - also be related, in part, to falling average family size?

I thank Professor Geoffrey Rose and Dr Eve Roman for helpful comments on the manuscript, Helen Edwards for typing it, and Amanda Sutton for helping with the calculations.

\section{References}

${ }^{1}$ Beral V. Parity and suceptibility to cancer. In: Fetal antigens and cancer (Ciba Foundation Symposium 96). London: Pitman, 1983; 182-203.

${ }^{2}$ Registrar General's Statistical Review of England and Wales 1938. London: HMSO, 1940.

${ }^{3}$ Registrar General's Statistical Review of England and Wales 1939-60. London; HMSO, 1941-62.

${ }^{4}$ Registrar General's Office. Census 1961. England and Wales. Fertility Tables. London: HMSO, 1966.
${ }^{5}$ Bailar JC III, Ederer F. Significance factors for the ratio of a Poisson variable to its expectation. Biometrics 1964; 20: $639-47$.

${ }^{6}$ Bernstein RA, Werner LH, Rimm AA. Relationship of gallbladder disease to parity, obesity and age. Health Serv Res 1973; 88: 925-36.

${ }^{7}$ Scragg RKR, McMichael AJ, Seamark RF. Oral contraceptives, pregnancy and endogenous oestrogen in gallstone disease- a case-control study. Br Med J 1984; 288: 1795-99.

${ }^{8}$ West KM. Epidemiology of diabetes and its vascular lesions. New York; Elsevier, 1978; 221-4.

${ }^{9}$ Beard CM, Fuster V, Annegers JF. Reproductive history in women with coronary heart disease. $A m \mathrm{~J}$ Epidemiol 1984; 120: 108-14.

${ }^{10}$ Miall WE, Oldham PD. Factors influencing arterial blood pressure in the general population. Clinical Science 1958; 17: 409-44.

${ }^{11}$ Winkelstein W, Rekate AC. Age trend of mortality from coronary artery disease in women and observations on the reproductive patterns of those affected. Am Heart J 1964; 67: 481-8.

${ }^{12}$ Office of Population Censuses and Surveys. Longitudinal study. Series LS, No 1, London: HMSO, 1982.

${ }^{13}$ Heliövaara M, Aromaa A. Parity and obesity.J Epidemiol Community Health 1981; 35: 197-9.

${ }^{14}$ McKeown T, Record RG. An examination of fertility of women following pregnancy according to height and weight. Br J Prev Soc Med 1957; 11: 102-5.

${ }^{15}$ Roman E, Beral V, Inskip H, McDowall M, Adelstein A. A comparison of standardized and proportional mortality ratios. Statistics in Medicine 1984; 3: 7-14.

${ }^{16}$ Royal College of General Practitioners. Oral contraceptives and health. London: Pitman Medical, 1974.

${ }^{17}$ Royal College of General Practitioners' Oral Contraception Study. Further analyses of mortality in oral contraceptive users. Lancet 1981 ; i: 541-6.

${ }^{18}$ Vessey MP, Doll R, Peto R, Johnson B, Wiggins P. A long term follow up study of women using different methods of contraception-an interim report.J Biosocial Science 1976; 8: 373-427.

${ }^{19}$ Vessey MP, Lawless M, McPherson K, Yeates D. Neoplasia of the cervix uteri and contraception: a possible adverse effect of the pill. Lancet 1983; ii: 930-4.

${ }^{20}$ Wynn V, Adams PW, Godsland I, Melrose J, Niththyananthan R, Oakley NW, Seed M. Comparison of effects of different combined oral contraceptive formulations on carbohydrate and lipid metabolism. Lancet 1979; i: 1045-9.

${ }^{21}$ Henderson BE, Casagrande JT, Pike MC, Mack T, Rosario I, Duke A. The epidemiology of endometrial cancer in young women. Br J Cancer 1983; 47: 749-56.

${ }^{22}$ Hildreth NG, Kelsey JL, LiVolsi VA, Fischer DB, Holford TR, Mostow ED, Schwartz PE, White C. An epidemiologic study of epithelial carcinoma of the ovary. Am J Epidemiol 1981; 114: 398-405.

${ }^{23}$ Beral V, Fraser P, Chilvers C. Does pregnancy protect against ovarian cancer? Lancet 1978; i: 1083-7.

24 Wigle DT. Breast cancer and fertility trends in Canada. Am J Epidemiol 1977; 105: 428-38.

${ }^{25}$ Marmot MG, Booth M, Beral V. Changes in heart disease mortality in England and Wales and other countries. Health Trends 1981; 13: 33-8. 